\section{EMBRYARIDDLE}

Aeronautical University

SCHOLARLY COMMONS
Journal of Aviation/Aerospace

Education \& Research

Volume 28

Number 2 JAAER 2019

Article 1

2019

\title{
Development of a Statistical Model to Predict Australian Flight Students' Valuation of Aviation Safety
}

Michael Chiu

University of South Australia, michaelchiu1103@gmail.com

Nickolai Isaksen

University of South Australia, nickolaiisaksen@hotmail.com

Steven Leib

University of South Australia, steve.leib@unisa.edu.au

Follow this and additional works at: https://commons.erau.edu/jaaer

Part of the Aviation and Space Education Commons, and the Aviation Safety and Security Commons

\section{Scholarly Commons Citation}

Chiu, M., Isaksen, N., \& Leib, S. (2019). Development of a Statistical Model to Predict Australian Flight Students' Valuation of Aviation Safety. Journal of Aviation/Aerospace Education \& Research, 28(2). https://doi.org/10.15394/jaaer.2019.1779

This Article is brought to you for free and open access by the Journals at Scholarly Commons. It has been accepted for inclusion in Journal of Aviation/Aerospace Education \& Research by an authorized administrator of Scholarly Commons. For more information, please contact commons@erau.edu. 


\section{Introduction}

A safer aviation industry, from training to air transport, is in everyone's best interest. The development of a positive safety culture as part of a robust Safety Management System is an important part of assuring aviation safety (International Civil Aviation Organization [ICAO], 2013a). A clearer understanding of individual attitudes, and how they are composed, may be insightful to help establish the context of safety culture.

A more focused look at individual attitudes, and their relationship to safety culture as a whole, solicits the need to consider the practical application of the value of individual attitudes. Flight schools, as one stakeholder group, have a vested interest in working with students that have both a high chance of success in training and the least possible liability; a flight student's own attitude toward safety and engagement in safe behaviors are valued attributes.

Complicating the issue of culture and its effect on the overall operation of SMS is the complex relationship between individual and collective thinking: the idea of a collection of individual attitudes being equivalent to group-level culture is neither assumed nor well understood. Much attention has shifted to the role of culture in an SMS that operates as intended - and safety culture is a notable subset (Leib \& Lu, 2013). However, the introduction of the human element is notoriously difficult to isolate given the inherent entanglement of culture, organizational structure, and processes (Guldenmund, 2007). This presents both a conceptual and a methodological challenge, with research often emphasizing either individual attitudes or group-level values without accommodating the other (Leung \& Cohen, 2011).

Bearing in mind the interrelationship of culture, organizational structure, and processes as well as the need to better understand individual/collective values, understanding safety culture should begin by observing these phenomena as independently as possible. Research of this 
nature has already been done: Adjekum (2014), Siu, Phillips, and Leung (2003), Freiwald, LenzAnderson, and Baker (2013), Dutcher (2001), and others have assessed individual attitudes toward safety and safety culture.

The purpose of this study was to explore the development of a predictive model to determine which factors were more significant in a flight student's valuation of safety. A better understanding of the more relevant factors of one's attitude toward safety can help aviation organizations make informed decisions to direct resources to support individual flight students' safety behaviors. Additionally, it may provide a dimension of assistance for the candidate selection process at organizations that are space- and resource-constrained. Lastly, this study is intended to stimulate future research linking safety attitudes with the development of a positive safety culture.

\section{Review of Literature}

\section{Safety Culture}

Safety culture itself is a complicated construct, and many have tried to define it with varying degrees of specificity. The Commercial Aviation Safety Team of the European Strategic Safety Initiative (Piers, Montijin, \& Balk, 2009) defines safety culture as a set of safety related attitudes, values, perceptions, and beliefs that are typically shared among all members within an organization. In more generic terms, it represents the "way of doing things," and the priority of safety within a particular group (Uttal, 1983). One component of safety culture also reflects the commitment to engage in safety-related behaviors (Federal Aviation Administration [FAA], 2007), and Ek, Akselsson, Arvidsson, and Johansson (2007) found that commitment includes the ability and willingness to prevent safety risk as well as the awareness to avoid the occurrence of safety risk. 
Although the concept of safety culture can be considered fairly nebulous, it is undoubtedly a fundamental component of an organization's ability to manage safety related issues (Glendon \& Stanton, 2000), and it is a key factor in determining whether an organization is successfully managing safety (Bailey, 1997; Kennedy \& Kirwan, 1998). ICAO (2006) indicates that the level of operational safety can be maximized by a positive safety culture by encouraging members within an organization to respect each other and create a harmonious working environment (Simon \& Cistaro, 2009). Moreover, it enables all members within the group to be treated fairly and equally by empowering responsibility and authority (Bos \& Lu, 2007). Because of these properties, the operational risks and errors are more likely to be anticipated if a positive safety culture is successfully installed in the organization (Stolzer, Halford \& Goglia, 2008). Given this, the importance of a positive safety culture at an aviation organization cannot be understated. It is understandable then that von Thaden and Gibbons (2008) have indicated that safety culture related research is a valuable part of understanding of organizational performance and procedures.

From both an operational and academic standpoint, safety culture and safety climate are closely related concepts that share a similar abstract idea (Reichers \& Schneider, 1990), but are nonetheless distinguishable from each other. As suggested by Guldenmund (2007), they are inseparable components in an organization that help measure the importance of safety by adopting different approaches. However, the difference between the two concepts lies in that safety climate is derived from safety culture and should be considered the dimension of safety culture that can be observed directly in an organization (Schein, 2004). Simply put, where "safety culture" describes the overall collective attitude toward safety at an organization, "safety climate" can be a snapshot of safety perception at any given time. Along these lines, 
Guldenmund (2007) notes that research on safety climate is basically research on attitudes. From a methodological perspective, it is difficult to discern whether answers provided by respondents reflect culture itself or attitudes from which to make inferences about culture, and conclusions from this kind of methodology should be drawn carefully.

Safety culture can be divided into more discrete components, which provide both a clearer understanding of the composition of safety culture as well as a methodological framework for researching safety culture. These five safety sub-cultures consist of informed culture, reporting culture, just culture, flexible culture, and learning culture (Reason, 2000). Informed culture represents the personnel's awareness of factors within an organization that threaten safety, including but not limited to working environment, operational equipment, and other staff members. Reporting culture is considered one's willingness to report safety related issues. It is built upon by establishing a blame-free environment and maintaining confidentiality of the people who initiated the reports. A just culture includes a reporting environment where unintentional errors are not punished. However, a line has to be drawn to establish unintentional errors from deliberate acts of malice, and disciplinary actions should be taken if the latter occurs. Flexible culture is indicated by the ability of an organization to change and adapt to a new working environment (Reason, 1997). Finally, learning culture reflects an organization's eagerness to learn from mistakes and improve overall performance (Weick, 1987). Nevertheless, it is important to notice that the five sub-cultures listed above are inter-dependent to each other, and should one of them fail to be present, the other components would be significantly degraded.

While these various safety sub-cultures can provide a more concrete understanding of what a safety culture is, it is another (and more complicated) matter to assess, predict, and influence safety culture. 


\section{Assessing, Influencing, and Predicting Safety Culture}

Considering the importance of safety culture to an organization, it is useful to discuss how safety culture can be influenced, as well as which factors have been demonstrated to meaningfully impact safety culture. This tends to be very difficult, as what predicts and/or influences safety culture may vary depending on the industry and organization. Guldenmund (2007) describes behavior at an organization ultimately as a product of the combination of culture, structure, and processes, all of which are related:

...any organization's culture cannot be isolated from its structure or processes. In carrying out the processes and coping with difficulties groups of people develop a culture, either despite of or because of some particular structure. (p. 737)

The relationship between culture and structure may be broadly relevant across industries, especially those that depend on a strong safety culture such as aviation or medicine. Yet, Thorp et al. (2012) found that the number of workers' compensation claims to be a significant predictor of safety culture at hospitals; one that does not exist in the aviation industry. It is not independent from other organizational aspects, and may be industry specific, which provides some explanation as to the difficulty of observing and measuring changes to safety culture.

Given that culture is both fostered and constrained by structure and processes, it is not surprising that safety culture can be influenced by changes to operations (Ek et al., 2007). For example, transitioning the focus of a business model to cost-effectiveness can result in an alteration of organizational behavior and weaken the state of safety, possibly leading to the occurrence of an incident or accident (Rasmussen, 1997). Even the roles of staff and different natures of job positions can lead to distinctive safety culture among groups even within the same 
organization. Adjekum (2014) found that the safety culture specifically of the front-line operational personnel, including flight students and flight instructors, have a strong impact on successful safety management at an aviation organization. Ek et al. (2007) demonstrated that the top-level management's commitment to safety can be inconsistent with the safety attitude of the lower-ranked staff because of the difference in the associated responsibilities. On the other hand, operational staff may perceive risks more accurately and exhibit better reporting behavior when compared to administrative staff due to the exposure to safety risks. Factors such as staff duties and proximity to risks and hazards can often be a direct function of management's decisionmaking at organizations. Differences in the strength of safety culture in different employee groups and at different levels is consistent with Guldenmund's (2007) description of the culturestructures-processes model, considering their weights change at different organizational levels. There is certainly the potential for individual attitudes toward safety to vary, and, as indicated by Cooper (2000), this possible deviation in values and attitudes can become an obstacle to maintaining a safe organization. It is worth noting that the linkage of safety culture, structures, and processes, suggests that, to at least some extent, safety culture can be consciously influenced. With this consideration, safety training can play a meaningful role in influencing safety culture. Safety training at an aviation organization is largely dependent on the legal requirements of the aviation regulator of its state. However, since the development of the Safety Management Manual (SMM), a comprehensive Safety Management Systems (SMS) guidebook (ICAO, 2006), SMS, including safety training, has experienced sustained growth across global aviation organizations. This has been accelerated by the development of international safety management standards and recommended practices (SARPs): ICAO Annex 19: Safety Management (ICAO, 2013b). Though ICAO standards constitute a non-legally binding body of policies and 
procedures, they are generally treated as regulatory in nature by the vast majority of participating states, which have developed their own legally-binding legislation mirroring the ICAO SARPs. The current $3^{\text {rd }}$ edition of the Safety Management Manual (SMM) covers a wide range of SMS details, including the theoretical basis for safety risk management, the importance of safety culture and organizational factors, and the practical guidelines for implementation and operation of a Safety Management System. This includes a well-developed discussion of the importance, need, and recommendations for Safety Promotion, especially the establishment of SMS related training (ICAO, 2013a). Many states have adopted SMS training regulations, which are similar to (if not nearly the same) as what is outlined in the SMM.

Safety Management Systems training should, according to the SMM, cover a variety of safety aspects such as organizational policy and objectives, the safety risk management process, and methods of communication. It should also include training in safety philosophy and theory. Lastly, it must include practical aspects of participating in the organization's SMS, such as the process for submitting hazard reports, etc. (ICAO, 2013a).

There can be little doubt as to the informative component of SMS training; that is, the exchange of information directly related to the SMS. This includes awareness of the organization's expectations of individuals at all levels, how to participate in a hazard reporting system, and the stated policies and objectives of the leadership regarding safety. While safety training is expected to positively influence safety culture (ICAO, 2013a), little research has explored the connection between increased training and individual valuation of safety.

\section{The Role of the Individual in Safety Culture}

Safety culture is a description of the collective. While it does not make sense to describe an individual as having a "safety culture," the role of the individual in the development of safety 
should not be ignored. Dutcher, Carrick, and Smith (2003) found that individual attitudes are very relevant to understanding the development of safety culture and, just as importantly, may be a more accurate assessment of safety culture than traditional statistics of accident and incident rates. Given the importance of safety culture as a whole on an organization's successful safety management, and with recognition that safety culture represents in part a collection of individual (potentially differing) attitudes, it is not unreasonable to suggest that research explore safety culture valuation at the individual level.

Individual demographic factors have been connected to aspects of safety culture. Ek et al. (2007) used factors such as gender, age, time in company, and time in position as potential factors that had an impact on how an individual employee perceived aspects of safety at an air traffic control organization. Though few significant effects were demonstrated between groups, the study investigated individuals' perceptions of the organization as a whole rather than address their own behavior.

Many studies have connected gender, age, etc. to safety and risk attitudes. Liu, Liu, Wang, Zhang, and Wang (2013), and Yavuz and Welch (2010), demonstrate examples of gender differences significantly affecting individuals' engagement in high-risk behavior and how they perceive safety measures in urban transit, respectively. The latter study even went so far as to suggest the need for development of gender-specific safety enhancements so as to maximize the safety benefit as perceived by men and women. Similarly, age has been demonstrated to be a meaningful distinction with safety attitudes. Siu et al. (2003) found significant differences between age groups of construction workers in Hong Kong with regard to safety attitude and safety performance. Sawacha, Naoum, and Fong (1999) found age, job experience, and training 
all to have strongly significant effects on safety performance. Dutcher (2001) found that pilot experience improved their perception of the importance of safety training.

Research has also explored behavior on the individual level with respect to safety subcultures, such as reporting culture. Chiang, Hsiao, Lin, and Lee (2011) found a correlation between level of reporting culture and the level of safety culture: hospital nurses who reported more frequently and in greater detail were found to be those with a higher level of safety valuation. Similarly, engagement (or participation) has also been found to be an important predictor of a strong safety culture, as a stronger reporting culture and aviation safety information seeking were demonstrated to be outcomes of high engagement (Chiang et al., 2011; Freiwald et al., 2013).

While there have been many studies that have looked at individual attitudes' relationship to safety concepts, predicting the strength of safety culture itself is extraordinarily challenging. Frazier, Ludwig, Whitaker, and Roberts (2013) suggests that “...it is difficult to find a single survey that exhibits any predictive quality in actual safety performance or statistics" (p. 18). The present study does not attempt to predict safety culture, only an individual's valuation of safety; further research will be necessary to explore the link between attitudes of individuals and safety culture itself.

The present study sought to develop a predictive model for a flight student's valuation of safety as a function of research-based predictors of gender, amount of flight experience, extent of safety training, and engagement. In addition, to consider the influence of these factors in context, this study also sought to determine the baseline cultural level of safety valuation to establish whether a significant difference existed between local individuals and those with safety training and flight experience. 
The research questions for this study are as follows:

RQ1: Does safety valuation between flight students/recently trained pilots differ significantly from general Australian valuation of safety?

RQ2: How can flight student demographic and experience factors be used to develop a predictive model for Australian flight students' and recently trained pilots' valuation of safety?

\section{Methodology}

\section{Study Design}

This was a quantitative study that sought to develop a predictive model for valuation of safety on the basis of five possible factors: age, flight experience, gender, depth of safety training, and engagement. To answer RQ1, the study used a one-way ANOVA to determine whether the safety valuation of flight students/recently trained pilots differed significantly from local individuals who had no experience in aviation. In addition, to answer RQ2, significant factors were used to develop the best possible model of safety valuation using linear regression.

\section{Participants}

Two groups of participants were used in this study. One represented flight students and pilots having recently completed training. Qualified participants in this group were required to be at least 18 years of age, identify as culturally Australian, have not more than 250 hours of combined dual/solo flight experience (to ensure more recent training and student level of experience), and have received aviation safety training since starting their flight program. The second group of participants (for the purpose of RQ1) were local Australians. Qualified individuals had to self-identify as representing Australian culture and have no flight training or professional aviation background. A priori power analysis (using $\mathrm{G}^{*}$ Power) indicated that 
achieving statistical power of 0.8 with a 0.4 (large) effect size at a .05 significance level with two groups required a minimum total sample of 52 individuals.

Surveys for the aviation group of participants were disseminated through social media. This was to accommodate the inconsistent schedule of flight students and to appeal to that particular age group. Sharing a survey link through social media allowed for its distribution via researchers' social and professional networks to reach a higher number of potential participants. This recruitment method also afforded the opportunity to find participants not connected to any one particular flight school. Surveys for the local group were solicited in person in the city center of a major Australian city. Participants were recruited in a public space by researchers and asked to participate in the study using an iPad. This was done on a weekend day to increase the likelihood that the sample would accurately represent city locals.

\section{Survey Instrument}

The aviation participants were given a survey with the following components:

1. Basic non-identifying demographic questions - including gender, age, and flight experience. All were self-disclosed by participants and both age and flight experience were treated as continuous variables.

2. Safety valuation questions -15 survey items addressed safety valuation. This portion of the survey tool was adapted from Liao (2015) and included three sets of five items, touching on safety subcultures of just culture, reporting culture, and learning culture. These were assessed using a five-point Likert scale ranging from strongly disagree to strongly agree. 
3. Engagement questions - five survey items adapted from Thorp et al. (2012) addressed individuals' level of engagement with their training organization/employer. These items were also evaluated using a five-point Likert scale.

4. Safety Training questions - six survey items addressed the perceived quality of training that the students received. The safety training questions did not specify the time, form and location of training, only the participant's self-identified belief of the extent to which they received some form of training on that particular subject. The subjects from each question were adapted from ICAO (2013a) and an adapted four-point Likert scale ranging from not covered to covered in depth was used to solicit responses.

The second participant group, consisting of local Australians that had no aviation experience, received only the 15 -item safety valuation questions. Survey questions are listed in Appendix A.

\section{Results}

\section{Descriptive Statistics}

IBM SPSS Statistics 24 was used for all analysis. For the aviation group, a total of 27 qualified responses were received. This included two female and 25 male participants. Table 1 summarizes the means and standard deviations for the remaining demographic items as well as safety valuation, safety training, and engagement.

Table 1

Summary of Pilot Group Responses

\begin{tabular}{lll} 
Factor & Mean Responses & Standard Deviation \\
\hline Safety Valuation & 3.93 & .340 \\
\hline Age & 25.22 & 9.619 \\
\hline Flight Hours & 117.8 & 68.429 \\
\hline Safety Training & 1.534 & .7206 \\
\hline Engagement & 4.225 & .7158 \\
\hline
\end{tabular}


To ensure reliability of multiple survey items addressing single concepts, Cronbach's alpha reliability coefficients were obtained for Safety Valuation and Engagement. Safety Training was not included because safety training items were specifically addressing different aspects of training which may be emphasized differently at organizations. The coefficients for Safety Valuation and Engagement were determined to be .700 and .768, respectively.

\section{Comparison of Aviation and Non-Aviation Participants}

There were 30 participants in the non-aviation group representing local valuation of safety. The means and standard deviation for Safety Valuation (from Table 1) for the aviation group was found to be 3.93 and .340 , respectively. In addition, the mean and standard deviation of the non-aviation group of participants was found to be 3.84 and .530 , respectively, as indicated in Figure 1.

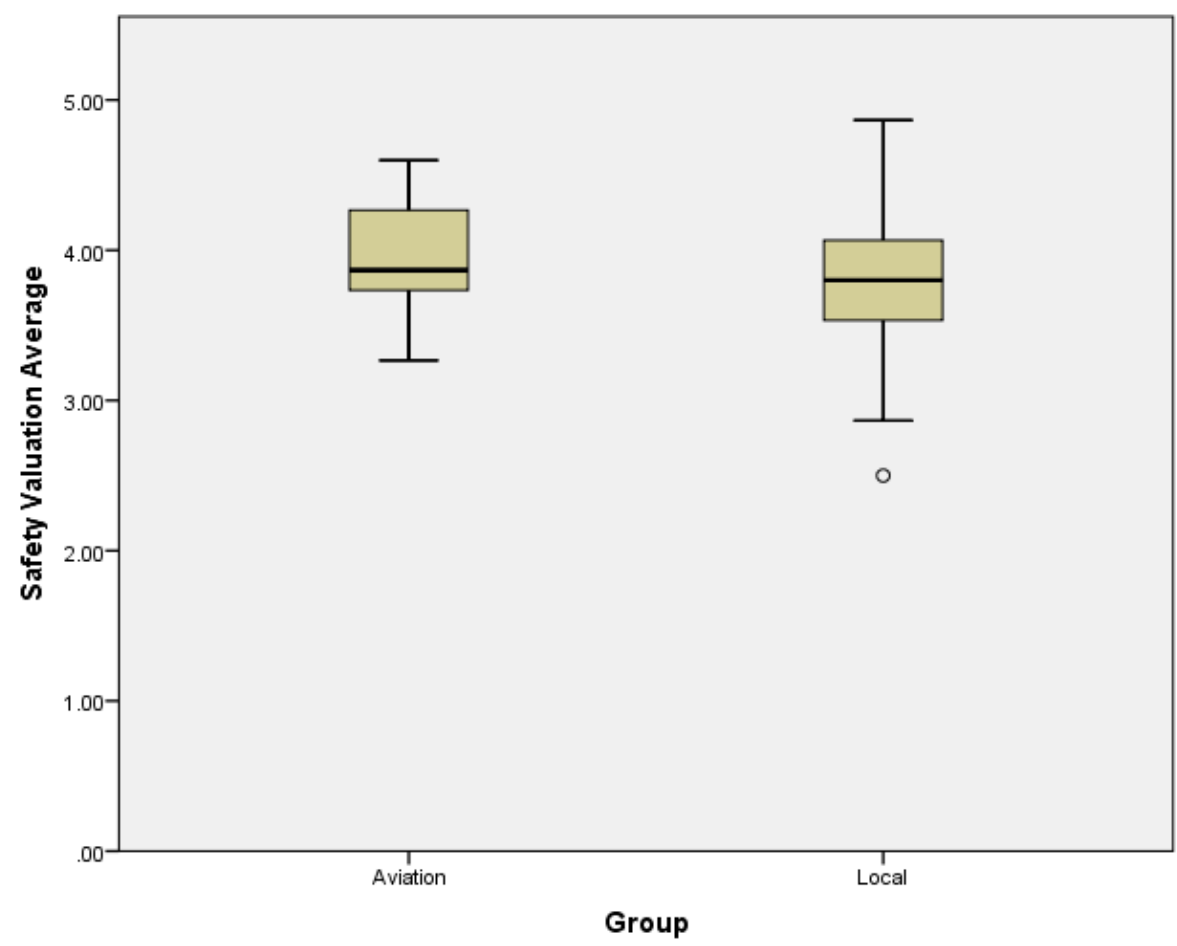

Figure 1. Boxplots of aviation and local groups' average Safety Valuation. 
A test of homogeneity of variances yielded a Levene Statistic of 1.817 corresponding to a .183 significance level, suggesting the assumption of homogeneity of variance was not violated.

The mean difference between the two groups was .101, which corresponded to an Fstatistic of .495 and a significance level of .485 , which was not significant at the .05 level.

\section{Regression}

Developing the regression model began with pre-selection of factors. A correlation matrix was developed among Safety Valuation and the five other potential factors to explore correlations and possible multicollinearity. Table 2 lists the observed correlations and significance values between Safety Valuation and Gender, Age, Flight Hours, Safety Training, and Engagement. For the purpose of analysis, Gender was coded as $1=$ Female, $2=$ Male.

Table 2

Correlations Potential Factors and Safety Valuation

\begin{tabular}{lcccccc} 
Variables & 1 & 2 & 3 & 4 & 5 & 6 \\
\hline 1. Safety Valuation & - & & & & & \\
\hline 2. Gender & -.175 & - & & & & \\
\hline 3. Age & -.128 & .073 & - & & & \\
\hline 4. Flight Hours & -.047 & -.094 & .030 & - & & \\
\hline 5. Safety Training & .008 & -.056 & .305 & -.062 & - & - \\
\hline 6. Engagement & $.450^{*}$ & -.204 & -.394 & -.114 & -.047 &
\end{tabular}
$* \mathrm{p}<.05$

With $\mathrm{p}=.027$, engagement was the only potential predictive factor that exhibited significance at the .05 level. In addition, there were no observed correlations between any of the potential factors at the .05 significance level, although Age and Engagement had a -..394 correlation with a significance level of .057.

Because of the lack of correlation between Safety Valuation and Age, Gender, Flight Hours, and Safety Training, only Engagement was selected for a regression model. Therefore, a 
simple linear regression was developed to predict Safety Valuation based on Engagement. A residuals plot for Engagement is shown in Figure 2, indicating the assumptions of linear regression were met.

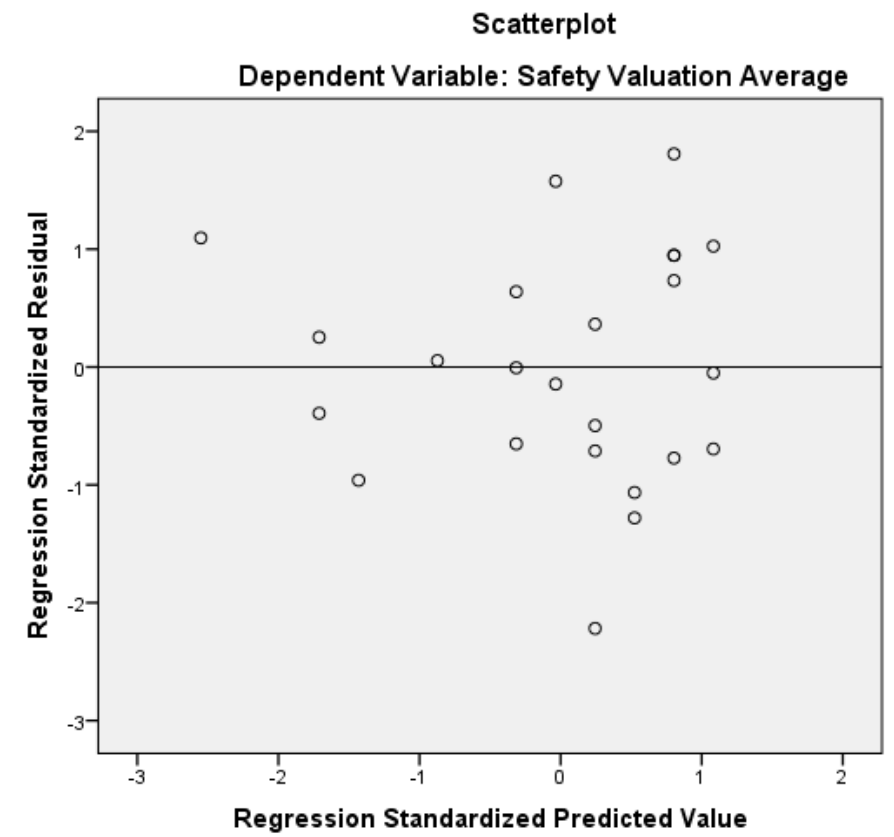

Figure 2. Residuals plot for Safety Valuation with Engagement as a predictor

Continuing the single-predictor regression model, Figure 3 shows the linear relationship between Engagement and Safety Valuation and the subsequent best-fit line. 


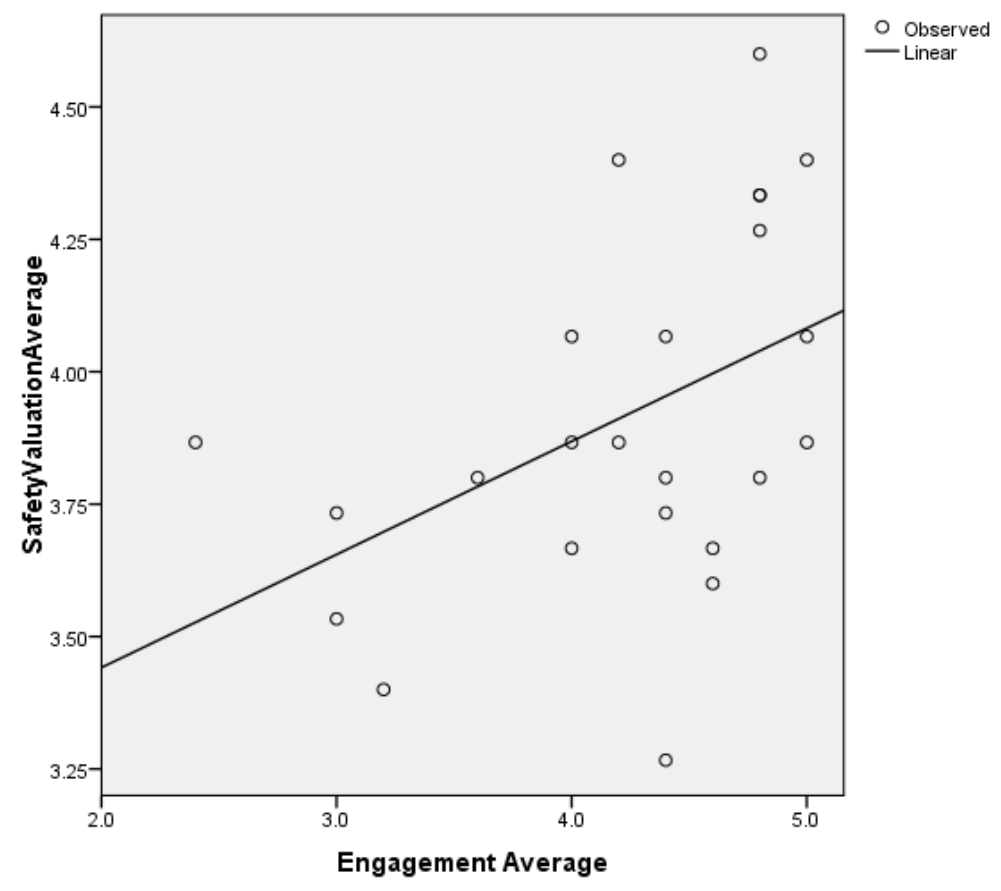

Figure 3. Linear relationship between Safety Valuation and Engagement.

A significant regression equation was found $(\mathrm{F}(1,22)=5.594, \mathrm{p}<.027)$ with an $R^{2}$ value of .203. The participants' predicted Safety Valuation was determined to be $3.014+.214$ (Engagement value) with both variables being measured on a 1-5 scale. The effect size $f^{2}$ was calculated to be .254 , corresponding to a medium to large effect size.

\section{Conclusions}

The first research question in this study sought to determine whether a significant difference existed between the Safety Valuation of the aviation group (flight students and recent pilot graduates) and local individuals. The study found that the Safety Valuation of Australian flight students/recently graduated pilots was not significantly different from local Australian individuals. A difference could not be shown despite this group received specific safety training and operate in a known high-risk, high-consequence field. 
Furthermore, the study (RQ2) tried to develop a predictive model for Safety Valuation based on research-guided potential factors. This study could not identify Age, Flight Hours, Gender, or Safety Training as predictors of the Safety Valuation of Australian flight students/recently trained pilots. As such, a single-variable linear regression using Engagement exhibits little to no predictive quality with regard to determining an individual's valuation of safety. However, as a single variable, Engagement was found to account for $20.3 \%$ of the change in Safety Valuation. These conclusions are further discussed in the following section.

\section{Discussion}

\section{Limitations}

There are several limitations of this study that are relevant to note. First, there are several methodological weaknesses that should be considered. Primarily, a larger sample size may have helped clarify some relationships between Safety Valuation and the possible predictive factors. While this is unlikely the case for Flight Hours and Safety Training (which had near-zero correlations to Safety Valuation), the additional factors of Age and Gender may significantly explain a portion of Safety Valuation with a larger sample. Along these lines, a greater sample size could help refine the portion of Safety Valuation explained by Engagement. Due to these limitations, this study should not be generalized to a greater population, especially in consideration of the cultural aspects discussed later in this section.

Another limitation of this study was the use and definition of Safety Valuation. For the purpose of this study, Safety Valuation was determined by the average surveyed strength of three safety culture sub-cultures (just culture, reporting culture, and learning culture). Although this study does not assume an inherent connection between Safety Valuation and safety culture (i.e. a group of individuals with a high safety valuation does not imply a positive safety culture), it does 
frame Safety Valuation in terms of relevant safety culture concepts applied on an individual level. Of course, further study is necessary to determine the connection (if any) between an individual's valuation of safety and a group's safety culture, especially considering the introduction of complex organizational processes and structures as components of a safety culture.

Lastly, this study was conducted in the context of the Australian flight training environment culture, and respondents self-identified as being representative of Australian culture. As to whether or not the sample genuinely reflected Australian culture is a greater methodological challenge that was beyond the scope of this study. Nonetheless, culture likely played a major role in the uniqueness of the results of this study, and this is further discussed later in this section. Recruitment of participants contributed to this limitation. Distribution of the survey to the pilot group via social media could have potentially excluded pilots who are not active on social media or were not in networks associated with the researchers. Furthermore, the in-person recruitment in a popular public space may have failed to identify certain segments of the local population.

\section{The Importance of Engagement}

One notable remark from the results of this study is the significance of Engagement as a predictor of safety valuation. Of the five possible predictors (Age, Flight Hours, Safety Training, Gender, and Engagement) of Safety Valuation, only Engagement was found to have a significant relationship. Much further study is necessary to understand the impact of what is likely a major predictor of an individual's safety valuation. Research topics, such as the genesis of an individual's engagement, what influences engagement, and the relationship between collective 
engagement and safety culture, are just three examples of directions for future research to better understand engagement and its implications to ensuring aviation safety.

\section{The Value of Safety Training}

This study found no significant relationship between the quality of safety training and safety valuation. Although this is a somewhat surprising result it is by no means conclusive with regard to an individual's valuation of safety. Even in the case that safety training genuinely does not explain one's valuation of safety, it likely still plays a critical role in the development of practical safety behaviors and the development of safety culture. Certainly, valuation of safety is not a prerequisite for safety compliance and safety action, and even in the absence of an effect on an individual's valuation of safety, it can provide information on procedures that impact behavior. The quality, quantity, frequency, and retention of safety training need to be the subject of intense further research, to help determine the effect it has on recipients and overall benefit to the organization.

\section{Cultural Replication}

This study was conducted in the context of Australian culture. Replication of this study in other cultural environments is strongly recommended. Results of this study could not demonstrate a significant difference in valuation of safety between local Australian individuals and those who had aviation training, including safety training. However, in another culture, one with perhaps a lower cultural level of safety valuation, effects of safety training, flight experience, and age might be demonstrated to be significant. In this regard, it is possible that a high level of cultural safety valuation may be a double-edged sword; a high level of inherent safety valuation is desirable but perhaps little can be done to increase it further, whereas in another cultural environment, the base cultural safety valuation might be low but could be 
actively constructed. The significance of cultural considerations in research - especially in a global industry - cannot be overstated. Much additional research is necessary to determine how culture impacts valuation of safety, the development of a safety culture, and safety assurance of operations. 


\section{References}

Adjekum, D. K. (2014). Safety culture perceptions in a collegiate aviation program: A systemic assessment. Journal of Aviation Technology and Engineering, 3(2), 44-56. https://doi.org/10.7771/2159-6670.1086

Bailey, C. (1997). Managerial factors related to safety program effectiveness: An update on the Minnesota Perception Survey. Professional Safety, 8, 33-35.

Bos, P., \& Lu, C-t. (2007, August/September). Safety management systems: A primer. AAAE Airport Magazine, 44-48.

Chiang, H-Y., Hsiao, Y-C., Lin, S-Y., \& Lee, H-F. (2011). Incident reporting culture: Scale development with validation and reliability and assessment of hospital nurses in Taiwan. International Journal for Quality in Health Care, 23(4), 429-436. https://doi.org/10.1093/intqhe/mzr031

Cooper, M. D. (2000). Towards a model of safety culture. Safety Science, 36, 111-136.

Dutcher, J. (2001). Attitudes toward flight safety at a regional gliding school (Atlantic). The University of Newcastle, Australia.

Dutcher, J., Carrick, K., \& Smith, S. (2003). Is your HPIAM programme really effective? The University of Newcastle, Australia.

Ek, A., Akselsson, R., Arvidsson, M., \& Johansson, C. R. (2007). Safety culture in Swedish air traffic control. Safety Science, 45(7), 791-811. https://doi.org/10.1016/j.ssci.2006.08.017

Federal Aviation Administration (FAA). (2007). Introduction to Safety Management Systems for Airport Operators (FAA Advisory Circular AC 150/5200-37A). Washington, DC: U.S. Government Printing Office. 
Frazier, C. B., Ludwig, T. D., Whitaker, B. G., \& Roberts, D. S. (2013). A hierarchical factor analysis of a safety culture survey. Journal of Safety Research, 45, 15-28. https://doi.org/10.1016/j.jsr.2012.10.015

Freiwald, D., Lenz-Anderson, C., \& Baker, E. (2013). Assessing safety culture within a flight training organization. Journal of Aviation/Aerospace Education \& Research, 22(2), 4157. https://doi.org/10.15394/jaaer.2013.1397

Glendon, A. I., \& Stanton, N. A. (2000). Perspectives on safety culture. Safety Science, 34(1- 3), 193-213.

Guldenmund, F. W. (2007). The use of questionnaires in safety culture research - an evaluation. Safety Science, 45(6), 723-743. https://doi.org/10.1016/j.ssci.2007.04.006

International Civil Aviation Organization (ICAO). (2006). Safety Management Manual (SMM) ( $1^{\text {st }}$ ed.). (Doc. 9859 AN/474). Montreal, Canada.

International Civil Aviation Organization (ICAO). (2013a). Safety Management Manual (SMM) ( $3^{\text {rd }}$ ed.). (Doc. 9859 AN/474). Montreal, Canada.

International Civil Aviation Organization (ICAO). (2013b). International Standards and Recommended Practices. The Convention on International Civil Aviation (Annex 19). Montreal, Canada.

Kennedy, R., \& Kirwan, B. (1998). Development of a hazard and operability-based method for identifying safety management vulnerabilities in high risk systems. Safety Science, 30(3), 249-274. https://doi.org/10.1016/s0925-7535(98)00025-3

Leib, S., \& Lu, C-t. (2013). A gap analysis of airport safety using ICAO SMS perspectives: A field study of Taiwan. Journal of Aviation Technology and Engineering, 2(2), 63-70. https://doi.org/10.7771/2159-6670.1078 
Leung, A. K.-Y., \& Cohen, D. (2011). Within- and between-culture variation: Individual differences and the cultural logics of honor, face, and dignity cultures. Journal of Personality and Social Psychology, 100(3), 507-526. https://doi.org/10.1037/a0022151

Liao, M.-Y. (2015). Safety culture in commercial aviation: Differences in perspective between Chinese and Western pilots. Safety Science, 79, 193-205. https://doi.org/10.1016/j.ssci.2015.05.011

Liu, C., Liu, W., Wang, Y., Zhang, Z., \& Wang, P. (2013). Patient safety culture in China: A case study in an outpatient setting in Beijing. BMJ Quality \& Safety, 23(7), 556-564. https://doi.org/10.1136/bmjqs-2013-002172

Piers, M., Montijin, C., \& Balk, A. (2009, March 6). Safety culture framework for the ECAST SMS-WG. Presented at the meeting of the European Commercial Aviation Safety Team of the European Strategic Safety Initiative (ESSI), Cologne, Germany.

Rasmussen, J. (1997). Risk management in a dynamic society: A modelling problem. Safety Science, 27, 183-213.

Reason, J. (1997). Managing the risks of organizational accidents. Aldershot, UK: Ashgate.

Reason, J. (2000). Safety paradoxes and safety culture. Injury Control \& Safety Promotion, 7(1), 3-14. https://doi.org/10.1076/1566-0974(200003)7:1;1-v;ft003

Reichers, A. E., \& Schneider, B. (1990). Climate and culture: An evolution of constructs. In B. Schneider (Ed.), Organizational climate and culture (pp. 5-39). San Francisco, CA: Jossey-Bass.

Sawacha, E., Naoum, S., \& Fong, D. (1999). Factors affecting safety performance on construction sites. International Journal of Project Management, 17(5), 309-315. https://doi.org/10.1016/s0263-7863(98)00042-8 
Schein, E. H. (2004). Organizational culture and leadership (3rd ed.). San Francisco, CA: Jossey-Bass.

Simon, S. I., \& Cistaro, P. A. (2009). Transforming safety culture: Grassroots led/management supported change at a major utility. Professional Safety, 28-35.

Siu, O.-1., Phillips, D. R., \& Leung, T.-w. (2003). Age differences in safety attitudes and safety performance in Hong Kong construction workers. Journal of Safety Research, 34(2), 199205. https://doi.org/10.1016/s0022-4375(02)00072-5

Stolzer, A. J., Halford, C. D., \& Goglia, J. J. (2008). Safety management systems in aviation. Burlington, VT: Ashgate.

von Thaden, T. L., \& Gibbons, A. M. (2008, July). The safety culture indicator scale measurement system (SCISMS). DOT/FAA/AR-01-G/015, Office of Aviation Research and Development, U.S. Department of Transportation, Federal Aviation Administration, Washington, DC.

Thorp, J., Baqai, W., Witters, D., Harter, J., Agrawal, S., Kanitkar, K., \& Pappas, J. (2012). Workplace engagement and workers' compensation claims as predictors for patient safety culture. Journal of Patient Safety, 8(4), 194-201. https://doi.org/10.1097/pts.0b013e3182699942

Uttal, B. (1983, October 17). The corporate culture vultures. Fortune Magazine.

Weick, K. E. (1987, Winter). Organizational culture as a source of high reliability. California Management Review, 29(2), 112-127. https://doi.org/10.2307/41165243

Yavuz, N., \& Welch, E. W. (2010). Addressing fear of crime in public space: Gender differences in reaction to safety measures in train transit. Urban Studies, 47(12), 2491-2515. https://doi.org/10.1177/0042098009359033 
Appendix A

Participant Survey

Section 1: Basic Demographic Information (given only to the aviation participant group)

- Gender

- Age

- Flight Hours

Section 2: Safety Valuation Questions (five-point Likert scale; adapted from Liao (2015); given to both participant groups in random order)

1. I understand which behaviours are acceptable and unacceptable with respect to safety.

2. I believe I would be treated fairly if my actions were unsafe.

3. I think it is important for people to learn that their actions have consequences and that they will be handled fairly.

4. I believe that behaviours are unsafe, not people themselves.

5. My relationships with people do not affect what safety issues I disclose (or would disclose).

6. I would be willing to disclose my own violations of safety regardless of if my behavior had been observed.

7. I would not hesitate to report someone's safety violations, even if believe they are more important or powerful than me.

8. I would report and unsafe action that I observed, even if I knew or was close with the person doing it.

9. I feel that reporting safety issues contributes to a safer environment for everyone.

10. I would report my own rule violations even if no one has noticed them.

11. I pay attention to safety information when I encounter it.

12. It is important to me that safety information is provided by companies/venues that I visit.

13. I try to find ways to enhance my safety knowledge on my own time.

14. If I have a safety concern, I am comfortable trying to resolve it.

15. I am willing to learn safety lessons from others.

Section 3: Engagement (adapted from Thorp et al. [2012]; given only to the aviation participant group in random order)

1. My instructor or someone at my flight training organization, cares about me as a person.

2. My flight training organization has employees that encourage my development.

3. My fellow students are committed to doing quality work.

4. In the past year, I feel I have had opportunities in flight training to learn and grow.

5. I have specific "school friends" that I know through flight training.

Section 4: Safety Training Topics (adapted from ICAO [2013a]; using an adapted four-point Likert scale including not covered, mentioned, somewhat covered, and covered in depth; given only to the aviation participant group in random order) 
1. Organisational Safety policies

2. Organisation Goals and Objectives

3. Safety Risk Management Principles

4. Hazard Reporting Systems

5. Safety Evaluation and Auditing

6. Lines of Communication for Disseminating Safety Information 